\title{
Austenite Nucleation and Growth Observed on the Level of Individual Grains by Three-Dimensional X-Ray Diffraction Microscopy
}

\begin{abstract}
V.I. SAVRAN, S.E. OFFERMAN, and J. SIETSMA
Austenite nucleation and growth is studied during continuous heating using three-dimensional X-ray diffraction (3-D XRD) microscopy at the European Synchrotron Radiation Facility (ESRF) (Grenoble, France). Unique in-situ observations of austenite nucleation and growth kinetics were made for two commercial medium-carbon low-alloy steels $(0.21$ and $0.35 \mathrm{wt}$ pct carbon with an initial microstructure of ferrite and pearlite). The measured austenite volume fraction as a function of temperature shows a two-step behavior for both steel grades: it starts with a rather fast pearlite-to-austenite transformation, which is followed by a more gradual ferrite-to-austenite transformation. The austenite nucleus density exhibits similar behavior, with a sharp increase during the first stage of the transformation and a more gradual increase in the nucleus density in the second stage for the $0.21 \mathrm{wt}$ pct carbon alloy. For the $0.35 \mathrm{wt}$ pct carbon alloy, no new nuclei form during the second stage. Three different types of growth of austenite grains in the ferrite/pearlite matrix were observed. The combination of detailed separate observations of both nucleation and growth provides unique quantitative information on the phase transformation kinetics during heating, i.e., austenite formation from ferrite and pearlite.
\end{abstract}

DOI: $10.1007 / \mathrm{s} 11661-009-0142-5$

(C) The Author(s) 2010. This article is published with open access at Springerlink.com

\section{INTRODUCTION}

AUSTENITE formation from an initial microstructure of ferrite and pearlite consists, as do most of the phase transformations, of two stages: nucleation and growth. So far, both the nucleation and the growth stage of austenite formation attracted limited attention, ${ }^{[1-4]}$ but the interest is continuously increasing due to the development of new types of steels such as dual-phase steel and transformation-induced plasticity steel. Based on earlier work, it is possible to establish the sequence of events constituting the ferrite/pearlite-to-austenite phase transformation. ${ }^{[1-5]}$ Austenite nucleates first on ferritepearlite grain boundaries and grows rapidly into the pearlite phase. Just above the $A_{1}$ temperature, these austenite grains form with the nearly eutectoid carbon concentration, according to thermodynamic equilibrium. The formation of austenite on the ferrite-ferrite grain boundaries at the early stages of the transformation (when only pearlite is expected to transform to austenite) was observed in Reference 5. In this case, austenite with a low carbon concentration compared to the equilibrium is formed. In the second stage of the phase transformation, primarily ferrite transforms to austenite, which slows down the overall rate of the

V.I. SAVRAN, Ph.D. Researcher, is with the Materials Innovation Institute M2i, 2628 CD Delft, The Netherlands. Contact e-mail: v.savran@m2i.nl S.E. OFFERMAN, Assistant Professor, and J. SIETSMA, Professor, are with the Department of Materials Science and Engineering, Delft University of Technology, 2628 CD Delft, The Netherlands.

Manuscript submitted June 12, 2008.

Article published online January 12, 2010 transformation. In the transformation of both pearlite to austenite and ferrite to austenite, the redistribution of carbon has to take place. There is, however, a distinct difference in the scale at which this takes place for the two transformations. In the case of the ferrite-toaustenite transformation, the carbon needs to redistribute over much larger distances than in the case of the pearlite-to-austenite transformation.

In the present work, the nucleation and growth of austenite from ferrite/pearlite structures is studied with a three-dimensional X-ray diffraction (3-D XRD) microscope employing high-energy synchrotron radiation. ${ }^{[6]}$ The advantage of this technique is that it offers the possibility of time-resolved measurements of the appearance (nucleation) and growth of individual austenite grains in the bulk of the material on a scale of micrometers at high temperatures, which is not possible with any other technique. Such observations provide a unique possibility of a quantitative study of the nucleation and growth rates of austenite in the bulk of the material.

\section{EXPERIMENTAL}

Two alloys, C22 and C35, were used in the experiments. The initial microstructures of the $\mathrm{C} 22$ and $\mathrm{C} 35$ alloys consisted of a ferrite and pearlite mixture with different phase volume fractions: the $\mathrm{C} 22$ alloy had 79 pct and the C35 alloy had 44 pct ferrite, and the remainder was pearlite (Figure 1). The chemical compositions of the studied alloys are shown in Table I. In order to minimize decarburization during the experiments, the samples were covered with a thin nickel 
coating and placed in a furnace with a helium flow. The samples are heated to $900{ }^{\circ} \mathrm{C}$ with a heating rate of $10{ }^{\circ} \mathrm{C} / \mathrm{min}$. In order to study the evolution of individual grains during the phase transformations, a small volume of the material is illuminated with a monochromatic beam of hard X-rays from the European Synchrotron Radiation Facility (ESRF) (Grenoble, France). ${ }^{[7,8]}$ For this purpose, the 3-D XRD microscope is used in the transmission geometry. The schematic representation of the experimental setup can be found in Reference 7 . The energy of the monochromatic X-rays is $80 \mathrm{keV}$ (wavelength of $1.55 \times 10^{-2} \mathrm{~nm}$ ). The beam size is $63 \times 70 \mu \mathrm{m}^{2}$, and the thickness of the samples is $400 \mu \mathrm{m}$ for the $\mathrm{C} 22$ and $1 \mathrm{~mm}$ for the C35 samples. By rotating the sample around an axis perpendicular to

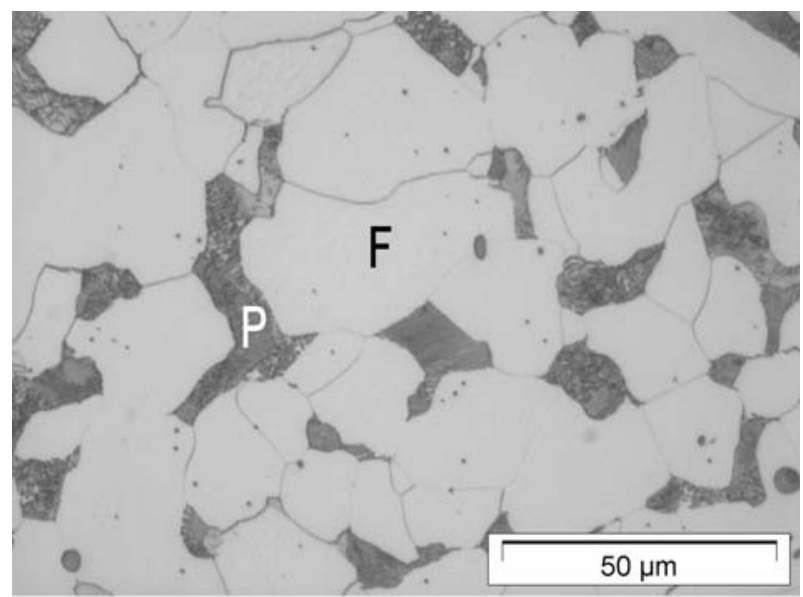

(a)

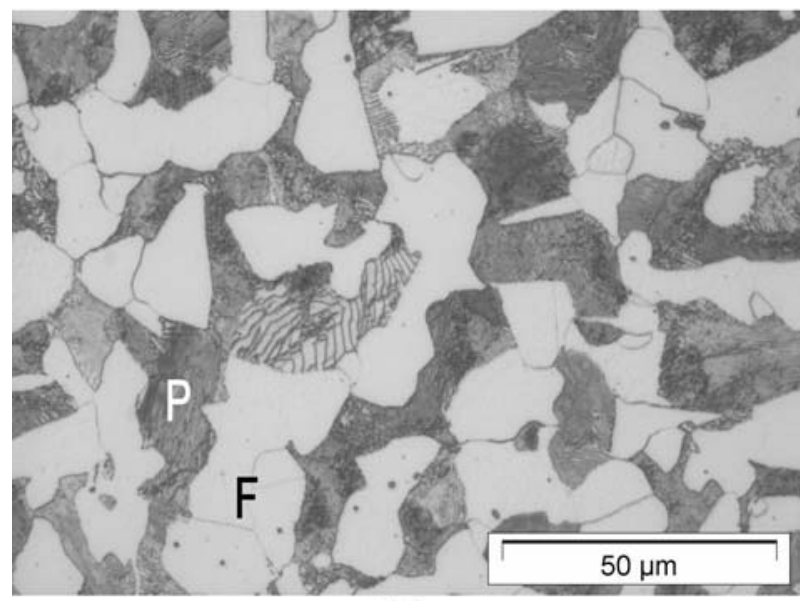

(b)

Fig. 1-Initial optical micrographs for (a) C22 and (b) C35 alloys. The $\mathrm{F}=$ ferrite (white) and $\mathrm{P}=$ pearlite (dark). the beam over an angle $\Delta \omega_{0}$ of $0.5 \mathrm{deg}$, a number of grains give rise to diffraction spots on a two-dimensional (2-D) detector. The exposure time is 1 second. Studying the appearance and the change in intensity of these individual spots as a function of the temperature during heating gives information about the austenite nucleation kinetics, the overall transformation behavior, and the growth rates for individual grains. At the given experimental conditions, the smallest detectable radius of an austenite grain is approximately $2 \mu \mathrm{m}$. Once every six exposures, the beam size is expanded to $90 \times 90 \mu \mathrm{m}^{2}$ in order to determine whether the total volume of the grain is illuminated in the small beam. In order to determine whether the total integrated intensity from a specific grain is measured in one rotation over $0.5 \mathrm{deg}$, as well as to determine whether the grain rotates (partly) out of the beam during the heat treatment, additional exposures are taken during the rotation over small angles of $0.5 \mathrm{deg}$, immediately before and after the central rotation $\Delta \omega_{0}$. Sudden (i.e., between consecutive exposures) grain rotations larger than $0.5 \mathrm{deg}$ are not expected during gradual heating without deformation at $10^{\circ} \mathrm{C} / \mathrm{min}$. The intensity of each individual spot is normalized with respect to the total intensity of the diffraction ring at the end of the transformation. By the repeated acquisition of images, the nucleation and growth of individual grains is studied with a typical resolution of a few seconds or, equivalently, less than $1 \mathrm{~K}$. The average austenite fraction during heating is obtained from the $\{200\}$ and $\{220\}$ powder rings obtained with the large beam size of $90 \times 90 \mu \mathrm{m}^{2}$, in order to have better statistics. More details on the data reduction can be found in References 7 and 8.

To determine the temperature during the experiments, a thermocouple was placed under the sample in close vicinity to it but not in contact with it. This gave rise to a difference in the temperature of the sample and the temperature measured using the thermocouple. The measured start and end temperatures of the transformation ( $A_{1}$ and $A_{3}$ temperatures, respectively) were more than $100{ }^{\circ} \mathrm{C}$ lower than the equivalent temperatures from the paraequilibrium phase diagram calculated with MTDATA*. In order to calibrate the

*MTDATA is a trademark of National Physical Laboratory, Teddington, UK.

temperature measurement obtained during the 3-D XRD experiment, additional dilatometric measurements were made. The dilatometric samples, cut from the same materials with a diameter of $5 \mathrm{~mm}$ and a length of $10 \mathrm{~mm}$, were heated using a high-frequency induction coil with a $10^{\circ} \mathrm{C} / \mathrm{min}$ heating rate to $900{ }^{\circ} \mathrm{C}$.

Table I. Composition of Alloys in Weight Percentages

\begin{tabular}{lcccccccccrrr}
\hline Alloy & $\mathrm{C}$ & $\mathrm{Mn}$ & $\mathrm{Si}$ & $\mathrm{Cu}$ & $\mathrm{Cr}$ & $\mathrm{Ni}$ & $\mathrm{Mo}$ & $\mathrm{Sn}$ & $\mathrm{P}$ & $\mathrm{S}$ & $\mathrm{Al}$ \\
\hline $\mathrm{C} 22$ & 0.214 & 0.513 & 0.200 & 0.086 & 0.021 & 0.049 & 0.003 & 0.003 & 0.019 & 0.031 & - \\
$\mathrm{C} 35$ & 0.364 & 0.656 & 0.305 & 0.226 & 0.177 & 0.092 & 0.016 & 0.017 & 0.014 & 0.021 & - \\
\hline
\end{tabular}


A thermocouple, spot welded on the sample, was used to control the temperature during the test. On the basis of the dilatometry results, the 3-D XRD measurements were shifted in temperature such that the start of the austenite formation measured using both the dilatometer and the 3-D XRD microscope coincided. The origin of the difference between the observed temperature and the sample temperature is based on the thermocouple not being in direct contact with the sample. The temperature gradient within the irradiated area of the sample (maximum $90 \times 90 \mu \mathrm{m}$ ) is, due to the good conductivity of the metal and the small irradiated area, not more than $1 \mathrm{~K}$.

\section{RESULTS AND DISCUSSION}

\section{A. Volume Fraction}

Figures 2(a) and (b) show the measured austenite volume fractions for the $\mathrm{C} 22$ and $\mathrm{C} 35$ alloys as a function of temperature compared to the paraequilibrium fractions obtained from MTDATA. There are remarkable similarities in the curves of Figure 2. All curves initially display a fast increase in the austenite fraction, which corresponds to the pearlite-to-austenite transformation, as was observed earlier. ${ }^{[1,2,5,9]}$ It is then followed by a slower increase in the austenite fraction,

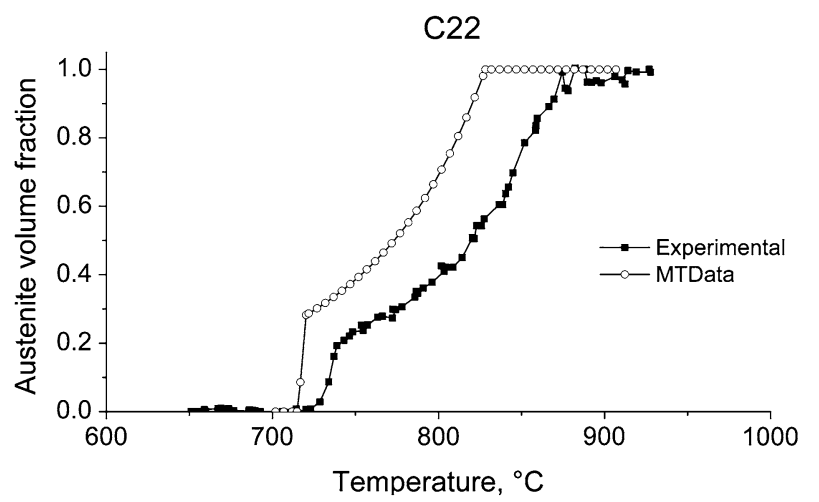

(a)

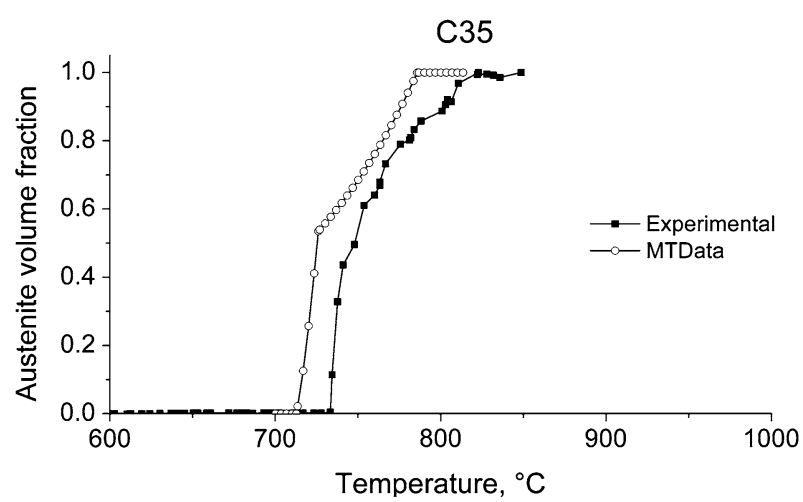

(b)

Fig. 2-Austenite volume fraction as measured by 3-D XRD (solid rectangles) and calculated using MTDATA (open circles) for (a) C22 and (b) C35 alloys. corresponding to the ferrite-to-austenite transformation. The slower part of the phase transformation appears, as will be shown later in the article, in both the nucleation and the growth behavior. It is related to the nucleation and growth in ferrite (rather than pearlite), which is slower because of the poor availability of carbon, making the austenite less stable. ${ }^{[5]}$ It is seen that the transition from fast to slow transformation coincides with the austenite fraction as calculated by MTDATA.

From Figure 2, it can also be seen that the formation of austenite starts approximately $15{ }^{\circ} \mathrm{C}$ higher than the $A_{1}$ temperature, as calculated with MTDATA for the C22 alloy, and approximately $20^{\circ} \mathrm{C}$ higher than the $A_{1}$ temperature for the $\mathrm{C} 35$ alloy. This overheating can be due to two causes. First, it is necessary to keep in mind that there is an uncertainty in the measured start temperature (the austenite volume fraction curve that was measured using the 3-D XRD microscope was shifted to a higher temperature to coincide with the start of the austenite formation as determined using dilatometry (Section II)). Dilatometry is a technique that measures the relative length change in the sample with respect to the temperature. A few percent of austenite has to be formed first in order to give rise to a signal on the dilatation curve, which can give rise to a slight temperature delay in the observation.

On the other hand, the observed overheating can to some extent be explained by the incubation (or induction) time for nucleation. As was described by Kashchiev ${ }^{[10]}$ after the initial supersaturation of the parent phase, some time, called induction time, may elapse prior to the formation of an appreciable amount of the new phase. This time is experimentally observable. The different experimental techniques detect the first formation of the new phase with a different resolution. In the present case, as was mentioned earlier, the detection limit of 3-D XRD microscopy is $2 \mu \mathrm{m}$. From the growth rate of the austenite grains in pearlite in the initial stage (which is found to be approximately $0.03 \mu \mathrm{m} / \mathrm{s}$, as will be described later in Section C), the estimated time for the nuclei to be detected is approximately 70 seconds. For the given heating conditions (heating rate $10{ }^{\circ} \mathrm{C} / \mathrm{min}$ ), this will lead to a delay of approximately $12{ }^{\circ} \mathrm{C}$ between the moment of nucleation and the detection of the austenite grain. The growth rate of austenite grains in ferrite is found to be approximately 15 times lower (i.e., $2 \mathrm{~nm} / \mathrm{s}$ (Section C)) than the growth rate of austenite in pearlite. In case we assume that below the detection limit $(2 \mu \mathrm{m})$ the austenite grains grow at the same rate as above the detection limit, that would mean that we observe the austenite grains more than 16 minutes (or equivalently $160{ }^{\circ} \mathrm{C}$ ) later than the moment at which they nucleated. This is not possible, because that would mean that the temperature at which austenite nucleation and early growth took place is well below the $A_{1}$ temperature, which is thermodynamically not possible. Such a discrepancy suggests that the rate at which the austenite grains grow into the ferrite is higher below than above the detection limit.

The consequences of the temperature uncertainty in the nucleation behavior in terms of the $\psi$ values will be discussed later in the article. 


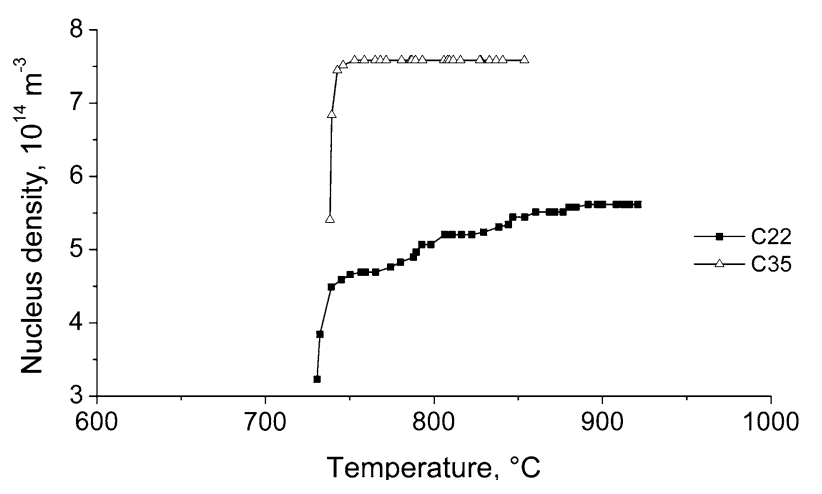

Fig. 3-Austenite nucleus density as a function of temperature for C22 (solid rectangles) and C35 (open triangles) alloys.

\section{B. Nucleation}

Figure 3 shows the measured nucleus density for $\mathrm{C} 22$ and C35 alloys as a function of temperature during continuous heating to the one-phase austenite region. The number of nuclei is determined from the number of austenite spots on the 2-D detector and is taken as an accumulative number. A more detailed description of the procedure can be found in Reference 7. Two different stages in the nucleation behavior are observed. Just after the beginning of the pearlite/ferrite-toaustenite transformation, there is a very fast increase in the number of austenite grains. Pearlite-ferrite (or pearlite-pearlite) grain boundaries are the most favorable places for the austenite nucleation for two reasons: the presence of the incoherent high-energy interface stimulates the heterogeneous nucleation, and the availability of carbon makes the newly formed nuclei stable. The nucleus density also depends on the number of potential nucleation sites. This is related to the density of the pearlite-pearlite or pearlite-ferrite grain boundary area and the shape and size of the grains. Taking into account that both studied alloys have approximately the same average grain size (Figure 1), for the C22 alloy the average pearlite volume fraction is lower than for the C35 alloy. Thus, even though both alloys feature a very sharp increase in the nucleus density in the initial stage of the transformation, the $\mathrm{C} 35$ alloy in total has a higher nucleus density in comparison to the C22 alloy.

After the first stage of the very sharp increase, which is related to the nucleation at pearlite-ferrite or pearlitepearlite grain boundaries, in the second stage of the transformation, when nucleation at the ferrite-ferrite grain boundaries takes place, the nucleus density continues to increase more gradually for the $\mathrm{C} 22$ alloy. Approximately $25 \mathrm{pct}$ of the nuclei are formed in this range. For the $\mathrm{C} 35$ alloy, no new nuclei appear to form, so the transformation proceeds further via the growth of already existing austenite grains into proeutectoid ferrite.

The further data analysis is performed using the classical nucleation theory (CNT). ${ }^{[1]}$ The CNT describes the steady-state nucleation rate per unit of volume by

$$
\frac{d N_{i}}{d t}=\left(1-f^{\prime}\right) N_{n, i} Z_{i} \beta_{i}^{*} \cdot \exp \left[-\frac{\Delta G_{i}^{*}}{\mathrm{k} T}\right]
$$

where

(1) $i$ indicates austenite nucleation from either pearlite or ferrite;

(2) $\left(1-f^{\prime}\right)$ takes into account the decrease in the number of potential nucleation sites with increasing austenite volume fraction, with $f^{\prime}$ the austenite volume fraction;

(3) $N_{n}$ is the density of potential nucleation sites;

(4) $Z$ is the nonequilibrium Zeldovich factor, which takes into account the reduction in the equilibrium concentration of subcritical nuclei due to the fact that some subcritical nuclei become supercritical during the nucleation (in our analysis, we assume $Z$ to be constant);

(5) $T$ is the temperature;

(6) $\mathrm{k}$ is the Boltzmann constant; and

(7) $\beta^{*}$ is the frequency factor, expressing the rate at which single atoms are added to the critical nucleus, which is given by ${ }^{[12]}$

$$
\beta^{*}=\frac{6 S^{*}}{a^{4}} D_{0} \exp \left(-\frac{Q}{\mathrm{k} T}\right)
$$

where $D_{0}$ is the pre-exponential factor of the diffusivity, $Q$ is the activation energy for the atom transfer across the nucleus-matrix interface (it is approximated by the activation energy for diffusion of iron atoms in ferrite and is taken to be $\left.3.93 \times 10^{-19} \mathrm{~J}\right){ }^{[13]} S^{*}$ is the area of the nucleus that can accept atoms, and $a$ is the average lattice parameter of ferrite.

The term $\Delta G^{*}$ is the activation energy for nucleation. In general, it can be written as ${ }^{[7]}$

$$
\Delta G_{i}^{*}=\frac{\psi_{i}}{\Delta g_{V}^{2}}
$$

where $\psi$ contains all the information about the shape of the nucleus (geometrical factors) and the energies $\sigma_{i}$ of the interfaces that are involved in the nucleation process, i.e., the newly formed interfaces and matrix interfaces where the nucleation took place, and $\Delta g_{V}$ is the difference in the Gibbs free energy per unit volume between the parent and the forming phase (driving force for nucleation).

Among all the variables used to calculate the nucleation rate, the $\psi$ parameter is the most difficult to establish. This parameter contains the information on the shape of the critical nucleus as well as the interfacial energies, parameters that are difficult or even impossible to measure experimentally, even with the modern techniques.

Nevertheless, there have been several theoretical and experimental attempts to estimate the value of the $\psi$ parameter. Clemm and Fisher ${ }^{[14]}$ proposed a model for the grain-corner nucleation of a nucleus that has an incoherent interface with the parent phase. In this model, four spherical caps form the nucleus at a grain corner and grow simultaneously into four parent grains. The $\psi$ value related to this type of grain-corner nucleation with incoherent phase boundaries between the nucleus and the matrix is predicted to be 
$3.3 \times 10^{-3} \mathrm{~J}^{3} / \mathrm{m}^{6}$, with values for the interface energy taken from the literature. Another model, which was used by Lange et al., ${ }^{[15]}$ assumes that ferrite nuclei mainly form on a grain face. In this case, the nucleus forms with coherent and partially coherent interfaces and thus requires a smaller activation energy for nucleation. The $\psi$ value found by Lange et al. for ferrite nucleation on austenite/austenite grain boundaries is $2.1 \times 10^{-6} \mathrm{~J}^{3} / \mathrm{m}^{6}$, based on their experimentally deduced values for the energy of the interfaces involved in the nucleation process. In a recent study on ferrite nucleation in an austenite matrix performed by Offerman et al., ${ }^{[7]}$ the value for $\psi$ is experimentally found to be $5 \times 10^{-8} \mathrm{~J}^{3} / \mathrm{m}^{6}$, which is much lower than the previously found model values. The underlying reason might be found in the formation of a nucleus that has a specific orientation relationship with one of the parent grains and that has nucleated at a grain corner, because Huang and Hillert ${ }^{[16]}$ experimentally found that grain corners are the most effective places for nucleation in carbon steels. It should be noted that in the experiment of Offerman et al. ${ }^{[7]}$ the position of the ferrite nuclei was not determined, but the experimental results show that one ferrite grain forms for each austenite grain, which suggests that the ferrite nuclei likely appear at the austenite grain corners.

In order to apply Eqs. [1] to [3] to the experimental data and to characterize the nucleation behavior by the $\psi$ value, the fraction of austenite nuclei formed on ferrite-ferrite grain boundaries is taken from the measured data (Figure 4). This is only done for the C22 alloy, because the experimental data for nucleation on ferrite grain boundaries in the C35 alloy is not enough to perform further analysis.

The driving force for nucleation is calculated using the MTDATA thermodynamic database. It is determined through the parallel-tangent construction under the assumption of the paraequilibrium condition (only carbon is considered to redistribute). The driving force for nucleation $\Delta g_{V}$, which is the change in Gibbs free energy due to the formation of an austenite nucleus in the ferrite matrix, is not trivial to find. The major challenge here is that the exact carbon content of the parent transforming phase (ferrite) at the interface is not known. The equilibrium phase diagram gives only the average carbon content in ferrite in equilibrium with austenite. If two phases (such as ferrite and austenite) both have equilibrium carbon values, there is no driving force for the transformation. In our analysis, we assume that the transforming ferrite phase has the equilibrium concentration of carbon in ferrite at the eutectoid temperature and that it does not change during the transformation. This is a reasonable assumption, because the change in the carbon concentration in ferrite is rather small during the whole transformation range. Although the resulting value for $\psi$ can be affected by this choice, the direct influence of the choice for the carbon concentration in ferrite on $\Delta G^{*}$ is very small. The austenite fraction is determined from the 3-D XRD measurements, as shown in Figure 2(a).

The normalized austenite nucleus density is determined only for the second part (nucleation at ferrite) of the nucleus density curve, because there is insufficient data to perform the analysis for the first part (nucleation at pearlite). Figure 4 shows the measured austenite nucleus density normalized to the maximum nucleus density as a function of the temperature.

The best fit of the experimental data to Eq. [1] gives $\psi_{f}=4.8 \pm 1.0 \times 10^{-8} \mathrm{~J}^{3} / \mathrm{m}^{6}$ for nucleation in the ferrite-to-austenite part of the transformation. In order to test the influence of the experimental uncertainty in the temperature scale, we also calculated $\psi_{f}$ for the case that the measured nucleus density was shifted to coincide with the $A_{1}$ temperature as calculated using thermodynamic databases. We then obtained a $\psi_{f}$ value of $1.1 \pm 0.5 \times 10^{-8} \mathrm{~J}^{3} / \mathrm{m}^{6}$. The two $\psi_{f}$ values are of the same order of magnitude as the value of the ferrite nucleation from the austenite determined by Offerman et al. $\left(5 \times 10^{-8} \mathrm{~J}^{3} / \mathrm{m}^{6[7]}\right)$ and are much lower than the model's predictions. ${ }^{[14,15]}$ Such a low value gives information about the specific nucleation conditions, such as that nucleation takes place in places that are high in energy (for example, triple edges and quadruple points) and that austenite nuclei form with relatively low interfacial energy. For the nucleation near the pearlite phase, as was mentioned earlier, we do not have

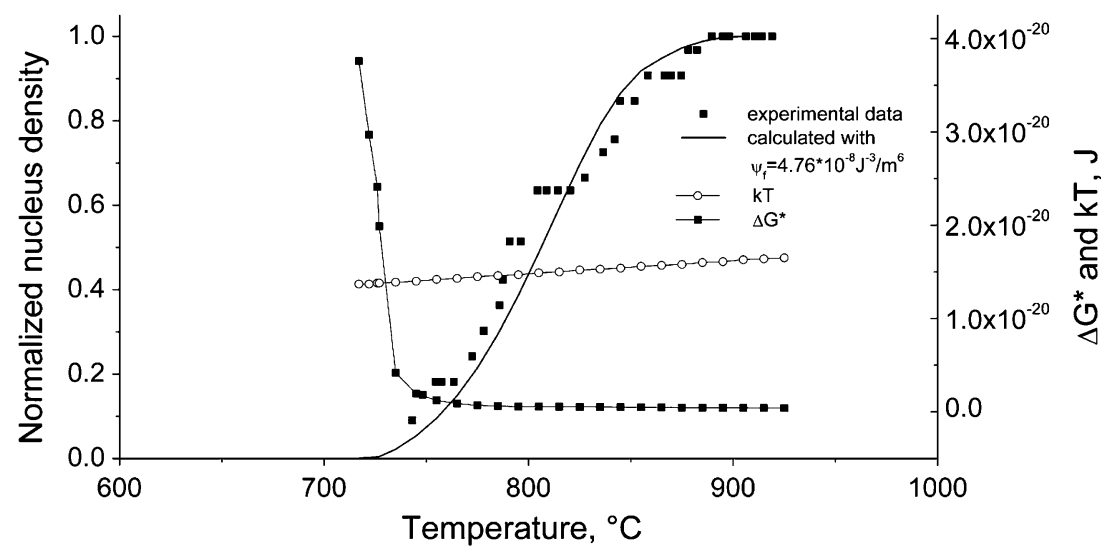

Fig. 4-Experimental and calculated values for the density of austenite nuclei on ferrite-ferrite grain boundaries, and $\mathrm{k} T$ and $\Delta G^{*}$ values as a function of temperature for the $\mathrm{C} 22$ alloy. Ferrite nucleus density is scaled to the maximum in experimental nucleation density. Solid line is a fit of experimental data to CNT. 
sufficient data to quantify the parameter $\psi_{p}$. However, qualitatively, we can expect it to be even lower than $\psi_{f}$. It is worth mentioning that by varying the activation energy of the diffusion $Q$ by a factor of 2 , we obtain $\psi_{f}$ of the same order of magnitude.

Figure 4 also shows that except for the first several degrees, for most of the transformation range, the calculated $\Delta G^{*}$ values are smaller than $\mathrm{k} T$, because with the increasing temperature, the driving force $\left(\Delta g_{V}\right)$ increases and the energy barrier decreases $\left(\Delta G^{*}\right)$. This implies that the observed nucleation behavior can be described by the CNT equations, but the resulting $\psi$ parameter is lower than the range assumed by the CNT and indicates barrierless nucleation. This qualitative conclusion is valid, even if the actual nucleation process cannot be physically described by the CNT. Regardless of the uncertainty in the value of $\psi_{f}$, it is clear that the activation energy for the austenite nucleation is very small. The reason for the small activation energy for nucleation could be that the energy needed to form a new interface is largely compensated by the energy that is removed from the system by eliminating the grain boundary of the parent phase in which nucleation takes place. Following Reference 17, it is possible to establish that for the given $\psi_{f}$ values, we get into the regime in which the activation energy for nucleation is smaller than $\mathrm{k} T$ but the critical nuclei are larger than a few atoms. Thus, for only the first several degrees of the transformation can the CNT approach be applied, but very little nucleation takes place in this regime. For most of the transformation range, however, application of the cluster dynamics approach, as described by Reference 17, is more appropriate. Defining $\gamma^{*}=\Delta G^{*} / \mathrm{k} T$, three different regimes can be identified, as follows.

(1) $\gamma^{*}>1$. This regime corresponds to the small overheating values. The critical nucleus size $n^{*}$ is then on the order of 10,000 atoms, including several hundred carbon atoms. If we assume a similar value for $\psi_{p}$ as was found for $\psi_{f}$, it is clear that in this range, only the nucleation at pearlite colonies can take place.

(2) $\gamma^{*} \approx 1$. This regime corresponds to the intermediate range. For this regime, the size of the critical nucleus is in the range of 300 to $\sim 800$ atoms.

(3) $\gamma^{*} \ll 1$. This regime corresponds to the large overheating values, e.g., $\Delta T=25^{\circ} \mathrm{C}$ and higher, in which more than 90 pct of the nucleation takes place. The critical nucleus size is approximately 100 to 200 atoms. With such a size, only a few carbon atoms are necessary to form the right composition. With increasing overheating, the critical nucleus size as well as the required carbon atoms in a nucleus will decrease.

The rather large size of the critical nuclei in the first degrees of the transformation gives insight into the differences in the nucleation behavior of the austenite grains nucleated near the source of carbon (pearlitepearlite or pearlite-ferrite grain boundaries (stage 1 in Figure 3)) and away from the source of carbon (ferriteferrite grain boundaries). In both cases, the $\psi_{f}$ values, and therefore the activation energy for nucleation, are very low, but the necessity of carbon atoms present in the nuclei makes the nucleation and further growth, necessary for observing the grains, near the source of carbon more favorable.

\section{Growth Types of Individual Grains}

Figure 5 shows three types of austenite grain growth as observed during the experiments. Each individual growth type exhibits one or more of the following growth kinetics.

(1) Growth kinetics I is fast growth (austenite growth in pearlite).

(2) Growth kinetics II is slow growth (austenite growth in ferrite).

(3) Growth kinetics III is extremely fast growth (massive growth).

Growth type A (Figure 5(a)) is similar to the overall transformation curves (compare with Figures 2(a) and (b)). Due to this similarity, it is possible to suggest that the transformation starts with the fast growth of austenite grains into the pearlite colonies (growth kinetics I) and continues as a slow ferrite-to-austenite transformation (growth kinetics II). The derived average pearlite-austenite interface (growth kinetics I) velocity, recalculated from the volume fraction of individual grains, assuming that the austenite grains grow spherically, is approximately $0.03 \mu \mathrm{m} / \mathrm{s}$. Following GaudeFugarolas and Bhadeshia, ${ }^{[18]}$ it is possible to estimate the average velocity of the austenite interface within the pearlite colony under diffusion-controlled growth, assuming that the growth rate is determined by the diffusion of carbon in austenite. At $740{ }^{\circ} \mathrm{C}$ for $\mathrm{Mn}$ steel, the paraequilibrium carbon concentrations in austenite on the austenite-cementite and the austenite-ferrite interfaces are $x_{\gamma \theta}^{\mathrm{Ceq}}=0.76 \mathrm{wt}$ pct and $x_{\gamma \alpha}^{\mathrm{Ceq}}=0.65 \mathrm{wt}$ pct, respectively, whereas the paraequilibrium carbon concentration in ferrite on the ferrite-austenite interface is $x_{\alpha \gamma}^{\mathrm{C} e q}=0.011 \mathrm{wt}$ pct. The diffusivity of carbon in austenite is $D_{\gamma}=6.24 \cdot 10^{-13} \mathrm{~m}^{2} / \mathrm{s}{ }^{[19]}$ For a typical value of the interlamellar spacing in pearlite $L=0.5 \mu \mathrm{m}$, the growth rate is estimated to be $1.4 \mu \mathrm{m} / \mathrm{s}$. The experimentally obtained value is more than an order of magnitude lower than the estimated value. Two possible reasons for this deviation can be imagined. The first one is related to cementite decomposition. In his work, Molinder ${ }^{[20]}$ estimated the activation energy for cementite decomposition at approximately $838 \mathrm{~kJ} / \mathrm{mol}$. This is much higher than the activation energy for the carbon diffusion in austenite, which is approximately $147 \mathrm{~kJ} / \mathrm{mol}$. A consequence of this is that the rate at which cementite decomposes is not sufficient to keep the carbon content in austenite at the equilibrium value and this leads to strong carbon-concentration gradients in the former pearlite (now austenite) areas. Indeed, a faster growth of austenite grains compared to the cementite dissolution is often observed after etching ${ }^{[1,2,5]}$ and obtained the name "pearlite ghosts." The second possible explanation for the lower transformation rate can be related to the pearlite-to-austenite transformation not being a purely diffusion-controlled transformation but having rather a 


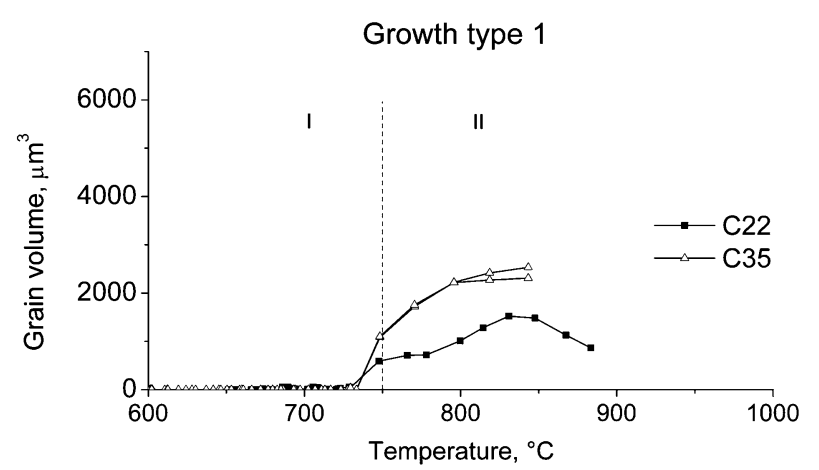

(a)

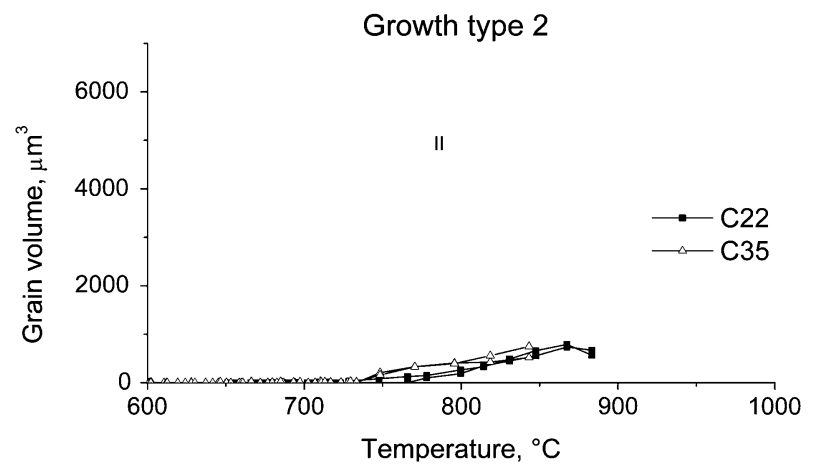

(b)

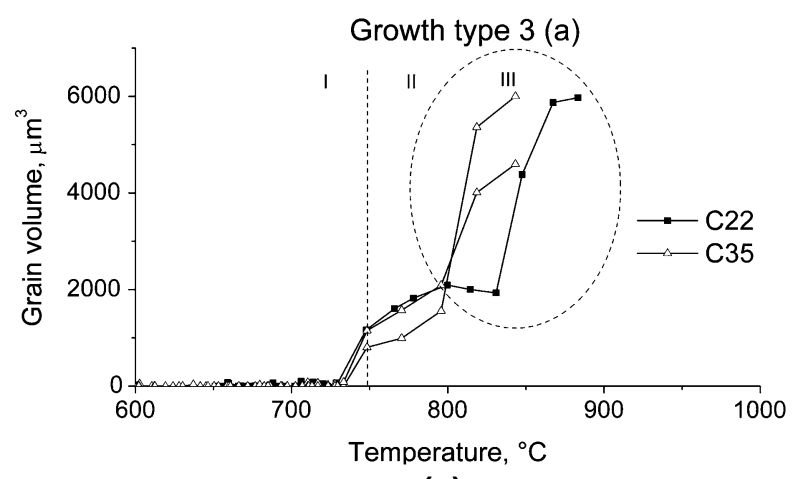

(c)

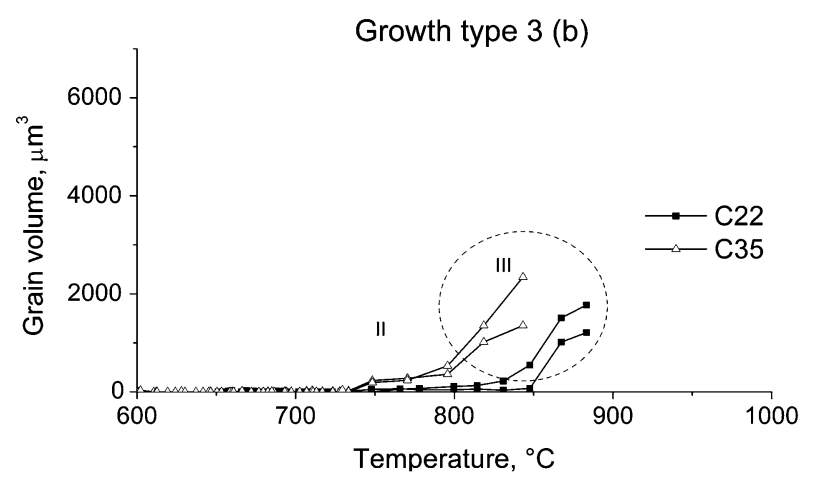

(d)

Fig. 5-Growth types: (a) fast growth into pearlite and (b) slow growth into ferrite. $(c)$ and $(d)$ are similar to (a) and (b), respectively, but with a growth acceleration in the last stages of the transformation. Open triangles are for $\mathrm{C} 35$ and solid rectangles for $\mathrm{C} 22$ alloys. I, II, and III indicate different growth kinetics.

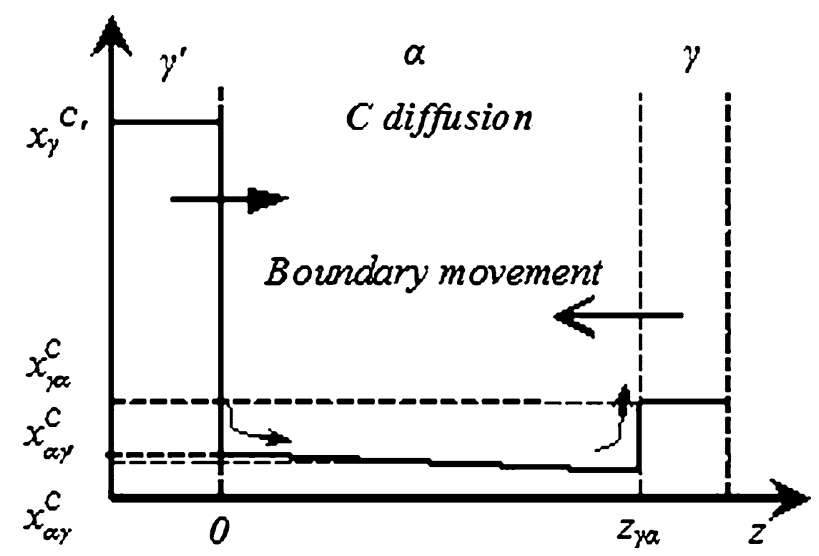

Fig. 6-Variation in the carbon content across the austenite-ferrite boundary. The $\alpha=$ ferrite, $\gamma=$ austenite formed on ferrite-ferrite grain boundary, and $\gamma^{\prime}=$ carbon-rich austenite formed in pearlite regions.

mixed-mode character. ${ }^{[21]}$ Diffusion-controlled transformation, the classical description of which is given by Zener, ${ }^{[22]}$ assumes that the diffusivity of an element (in this case, carbon) is finite, whereas the rate of transformation of the crystallographic lattice, which is described by the interface mobility, ${ }^{[11]}$ is infinitely large. In mixed-mode transformations, both the diffusivity and the interface mobility are finite, which leads to slower transformation kinetics.

Once all the pearlite has been consumed by austenite, the same austenite grains continue to grow further into the ferrite phase with the same crystallographic orientation, following growth kinetics II.

Growth type B consists only of growth kinetics II, and is attributed to the nucleation and growth of new grains on the ferrite-ferrite grain boundaries (Figure 5(b)). It was shown earlier ${ }^{[5]}$ that at the very early stages of the transformation, the formation of austenite on the ferrite-ferrite grain boundaries (at quadruple points, triple edges, and grain boundaries) can take place. In this case, there is no direct contact with the source of carbon, the (former) cementite phase, so carbon will be supplied from the areas rich in carbon through the ferrite matrix (Figure 6). Under the assumption that the growth is controlled by the diffusion of carbon in ferrite, the flux of carbon atoms can be expressed as

$$
J^{\alpha}=-D_{\mathrm{C} \alpha} \cdot\left(\frac{x_{\alpha \gamma^{\prime}}^{\mathrm{Ceq}}-x_{\alpha \gamma}^{\mathrm{Ceq}}}{z_{\gamma \alpha}}\right)
$$

where $D_{\mathrm{C} \alpha}$ is the temperature-dependent carbon-diffusion coefficient in ferrite, ${ }^{[23]} x_{\alpha, \gamma^{\prime}}^{\mathrm{C}}$ is the carbon concentration in ferrite on the grain boundary of ferrite with carbon-rich austenite (austenite formed in pearlite regions), and $z_{\gamma \alpha}$ is the position of the austenite-ferrite interface and is equal to the carbon diffusion distance from the source of the carbon (former pearlite phase) to the austenite nucleus. For the estimation of the typical growth rate, a value of $30 \mu \mathrm{m}$ is taken. 
The interface movement for the austenite grain growth on the ferrite-ferrite grain boundary can then be calculated as

$$
\frac{d z_{\gamma \alpha}}{d t}=-\frac{J^{\alpha}}{\left(x_{\gamma \alpha}^{\mathrm{Ceq}}-x_{\alpha \gamma}^{\mathrm{Ceq}}\right)}
$$

Taking the average diffusion distance equal to $30 \mu \mathrm{m}$ and solving Eqs. [4] and [5], it is possible to estimate the austenite-ferrite interface velocity. The average velocity of the austenite-ferrite interface for $\mathrm{C} 22$ alloy at $750{ }^{\circ} \mathrm{C}$ is expected to be $0.03 \mu \mathrm{m} / \mathrm{s}$.

The average austenite-ferrite interface (growth kinetics II) velocity derived from the 3-D XRD measurement is approximately equal to $0.002 \mu \mathrm{m} / \mathrm{s}$. Similar to the austenite growth from pearlite, this is an order of magnitude lower than the estimated value. The cause for the lower growth rate could be related to the change in the transformation mode from diffusion-controlled to mixed-mode transformation. The slow decrease in carbon content in the carbon-rich grains (austenite formed in the pearlite regions) due to slow carbon diffusion in austenite in combination with the longer diffusion distance slows down the transformation kinetics.

The peculiarity of growth type C (Figures 5(c) and (d)) is that at the final stages of the transformation, there is a strong acceleration of the process (growth kinetics III). The initial stages of the growth are similar to growth types A and B: growth from pearlite-ferrite grain boundaries (similar to growth type $\mathrm{A}$ and growth kinetics I, II) or from ferrite-ferrite grain boundaries (similar to growth type B and growth kinetics II). However, the acceleration of the transformation at the last stage of the transformation is remarkable. A possible explanation for such behavior is a change in the transformation mode from partitioning (below the $T_{0}$ temperature of the $\mathrm{Fe}-\mathrm{C}$ system) to massive transformation (above $T_{0}$ ). In the latter type of transformation, the original phase transforms to a new one with the same composition. In this case, the transformation proceeds rather fast, because the redistribution of elements (in this case, carbon) is not necessary. For the $\mathrm{C} 22$ alloy, the observed transition in growth behavior occurs at $T=850{ }^{\circ} \mathrm{C}$. At this temperature, the carbon content in ferrite $\left(\mathrm{C}_{\alpha}\right)$ and austenite $\left(\mathrm{C}_{\gamma}\right)$ for which both phases have the same Gibbs free energy, is equal to $0.022 \mathrm{wt}$ pct. Correspondingly, for the C35 alloy at $T=823{ }^{\circ} \mathrm{C}$, the equivalent carbon content is equal to $0.044 \mathrm{wt}$ pct. These are values that are only slightly higher than the equilibrium carbon content of the ferrite. The ferrite phase can actually have a carbon content that is higher than the equilibrium value when it is in contact with austenite that also contains more carbon than the equilibrium. ${ }^{[24,25]}$ This is likely the case at ferrite-austenite grain boundaries, because the austenite is initially formed with the pearlitic composition. Because no carbon redistribution is required, the character of the transformation then changes to the interface controlled. The approximate interface velocity increases to $0.015 \mu \mathrm{m} / \mathrm{s}$ in the regime of growth kinetics III.
The change in transformation mode from diffusion controlled to massive was observed by Schmidt et al., ${ }^{[26,27]}$ who studied the austenite formation from ferrite-pearlite microstructure during continuous heating using hot-stage confocal microscopy. During the experiments, under conditions above the $T_{0}$ temperature, the growth rate increased drastically and it was claimed that the interface-reaction-controlled growth mechanism was responsible for the transformation.

\section{CONCLUSIONS}

The following conclusions can be drawn from this study.

1. The austenite nucleus density as a function of temperature exhibits a two-stage behavior. It starts with a very sharp increase during the first degrees of the transformation, which is likely related to the austenite nucleation on pearlite-ferrite grain boundaries. In the second stage, there is a more gradual increase in the austenite nucleus density for the $\mathrm{C} 22$ alloy and no increase for the C35 alloy. This stage is likely related to austenite nucleation on ferriteferrite grain boundaries. It is found that within the framework of the CNT, the $\psi_{f}$ value, which represents the balance between the energy released by the elimination of the interfaces and the energy required for the formation of new interfaces, is much lower than models in the literature predict, and the resulting activation energy for nucleation is actually smaller than $\mathrm{k} T$.

2. Three different austenite grain-growth types were observed. Type A is similar to the overall transformation behavior, with a fast pearlite decomposition into austenite and a slow ferrite-to-austenite transformation. In this case, once an austenite grain consumed all the pearlite, it continues to grow further into proeutectoid ferrite with the same crystallographic orientation. Growth type B is related to the austenite nucleation and growth on ferrite-ferrite grain boundaries, away from the source of carbon. In this case, the formation of low-carbon austenite, compared to growth type A, as was observed in Reference 5, can be expected. For growth type C, an acceleration of the transformation at the last stages of the transformation is likely to be related to a change in the transformation mode, from partitioning to massive.

\section{ACKNOWLEDGMENTS}

This work is performed within the framework of the research program of the Materials Innovation Institute M2i (www.m2i.nl), Project No. MC5.03171. The support of Corus Research, Development \& Technology (IJmuiden, the Netherlands) for this project is acknowledged. We acknowledge the ESRF for the provision of synchrotron radiation facilities. The authors thank N.H. van Dijk (Interfaculty Reactor Institute, 
Delft University of Technology, Delft, Netherlands) for fruitful discussions on nucleation and S. Grigull (European Synchrotron Radiation Facility, Grenoble Cedex, France), L. Margulies and E.M. Lauridsen (Center for Fundamental Research: Metal Structures in 4D, Materials Research Department, Risø National Laboratory, Roskilde, Denmark), N.H. van Dijk, S. van der Zwaag (Aerospace Faculty, Delft University of Technology, Delft, Netherlands), and H.F. Poulsen (Center for Fundamental Research: Metal Structures in 4D, Materials Research Department, Risø National Laboratory, Roskilde, Denmark) for general support for the experimental part of this work.

\section{OPEN ACCESS}

This article is distributed under the terms of the Creative Commons Attribution Noncommercial License which permits any noncommercial use, distribution, and reproduction in any medium, provided the original author(s) and source are credited.

\section{REFERENCES}

1. G.A. Roberts and R.F. Mehl: Trans. ASM, 1943, vol. 31, pp. $613-50$.

2. G.R. Speich, V.A. Damarest, and R.L. Miller: Metall. Trans. A, 1981, vol. 12A, pp. 1419-28.

3. A. Jacot and M. Rappaz: Acta Mater., 1999, vol. 47 (5), pp. 1645-51.

4. T.A. Palmer and J.W. Elmer: Scripta Mater., 2005, vol. 53, pp. $535-40$

5. V.I. Savran, Y. van Leeuwen, D.N. Hanlon, C. Kwakernaak, W.G. Sloof, and J. Sietsma: Metall. Mater. Trans. A, 2007, vol. 38A, pp. 946-95.

6. H.F. Poulsen: Three-Dimensional X-Ray Diffraction Microscopy: Mapping Polycrystals and Their Dynamics, Springer, New York, NY, 2004, p. 156.
7. S.E. Offerman, N.H. van Dijk, J. Sietsma, S. Grigull, E.M. Lauridsen, L. Margulies, H.F. Poulsen, M.T. Rekveldt, and S. van der Zwaag: Science, 2002, vol. 298, pp. 1003-05.

8. S.E. Offerman, N.H. van Dijk, J. Sietsma, E.M. Lauridsen, L. Margulies, S. Grigull, H.F. Poulsen, and S. van der Zwaag: Acta Mater., 2004, vol. 52, pp. 4757-66.

9. C.R. Brooks: Principles of the Austenitization of Steels, Elsevier Applied Science, London, 1992, pp. 81-144.

10. D. Kashchiev: Nucleation: Basic Theory with Applications, Butterworth-Heinemann, Linacre House, 2000, pp. 100-50.

11. J.W. Christian: The Theory of Transformations in Metals and Alloys, Pergamon Press, Oxford, United Kingdom, 2002, pp. 422-80.

12. H.I. Aaronson and J.K. Lee: in Lectures on the Theory of Phase Transformations, H.I. Aaronson, ed., TMS, Warrendale, PA, 1999, 2nd ed., pp. 176-77.

13. J. Kučera and K. Stránský: Mater. Sci. Eng., 1952, vol. 52, pp. $1-38$.

14. P.C. Clemm and J.C. Fisher: Acta Metall., 1955, vol. 3, pp. 70-77.

15. W.F. Lange, III, M. Enomoto, and H.I. Aaronson: Metall. Trans. A, 1988, vol. 19A, pp. 427-40.

16. W. Huang and M. Hillert: Metall. Mater. Trans. A, 1996, vol. 27A, pp. 480-83.

17. N.H. van Dijk, S.E. Offerman, J. Sietsma, and S. van der Zwaag: Acta Mater., 2007, vol. 55, pp. 4489-98.

18. D. Gaude-Fugarolas and H.K.D.H. Bhadeshia: J. Mater. Sci., 2003, vol. 38, pp. 1195-201.

19. J. Ågren: Scripta Metall., 1986, vol. 20, pp. 1507-10.

20. G. Molinder: Acta Metall., 1956, vol. 4, pp. 565-71.

21. J. Sietsma and S. van der Zwaag: Acta Mater., 2004, vol. 52, pp. 4143-52.

22. C.J. Zener: J. Appl. Phys., 1949, vol. 20, pp. 950-53.

23. Handbook of Chemistry and Physics, CRC Press, Boca Raton, FL, 1989, pp. 51-87.

24. J.G. Speer, R.E. Hackenberg, B.C. Decooman, and D.K. Matlock: Philos. Mag. Lett., 2007, vol. 87, pp. 379-82.

25. M.J. Santofimia, L. Zhao, and J. Sietsma: Scripta Mater., 2008, vol. 59, pp. 159-62.

26. E. Schmidt, Y. Wang, and S. Sridhar: Metall. Mater. Trans. A, 2006, vol. 37A, pp. 1799-1810.

27. E.D. Schmidt, E.B. Damm, and S. Sridhar: Metall. Mater. Trans. A, 2007, vol. 38A, pp. 244-60. 